\title{
Glenoid size and Orientation in the Chilean Population
}

\author{
Tamaño y Orientación Glenoidea en la Población Chilena
}

\author{
Julio Contreras ${ }^{1,2}$; Rodrigo Liendo ${ }^{3,4}$; Manuel Beltrán ${ }^{1}$ \& Francisco Soza ${ }^{3,4}$
}

CONTRERAS, J. ; LIENDO, R.; BELTRÁN, M. \& SOZA, F. Glenoid size and orientation in the Chilean population. Int. J. Morphol., 38(4):956-962, 2020.

SUMMARY: Glenoid morphology is a key factor in determining the success of shoulder surgery. The purpose of this experimental study was to precisely determine the anatomical size and orientation of the glenoid in the Chilean population. 122 CT scans from asymptomatic Chilean patients were obtained. The mean age was 43.8 years (SD 12.3; range, 17-53 years) with 63 female and 59 male patients. For each of the scapulae, were obtained the glenoid version and inclination, maximum glenoid width and height, superior glenoid width, glenoid surface area, glenoid vault depth, and maximum scapular width. The glenoid size showed an average width of $26 \pm 2.7 \mathrm{~mm}$, a height of $40.3 \pm 3.5 \mathrm{~mm}$ and a vault depth of $26.5 \pm 3.7 \mathrm{~mm}$. There were significant differences between men and women. The glenoid orientation showed an average of $-13.9 \pm 4.8^{\circ}$ of retroversion and a superior inclination of $11.1 \pm 4.7^{\circ}$. Significant differences between men and women were seen only for version. We conclude, that in this Chilean sample the morphological parameters of the glenoid correspond to the published literature, however, some characteristics in this cohort must be further confirmed using other methods.

KEY WORDS: Shoulder Joint, Glenoid Cavity, Anatomy, Bone Retroversion.

\section{INTRODUCTION}

Glenoid morphology is a key factor in determining the success of shoulder surgery (Walch et al., 1999; Knowles et al., 2016). To date, no study of the glenoid morphology measuring both size and orientation has been performed in the Chilean population.

Shoulder arthroplasty has seen a dramatic increase in the past two decades because of evidence showing that this procedure can reduce pain and improve joint function (Knowles et al.). The survivorship of total shoulder arthroplasty at 15 years has been shown to be greater than $85 \%$, however, glenoid loosening remains a leading cause of prosthetic component failure (Walch et al.; Knowles et al.). Avoiding malposition of the glenoid component would be made easier if the surgeon were familiar with the morphology of the glenoid (Frankle et al., 2009).

Anatomic parameters of the glenoid relevant to prosthesis design and use include glenoid height, width, articular surface area, inclination, vault size and version (Strauss et al., 2009). A number of cadaveric studies have demonstrated considerable natural variability in these parameters (Churchill et al., 2001; Codsi et al., 2008;
Strauss et al.). Numerous studies have evaluated glenoid morphology and found variations amongst men and women, shoulder dominance, and activity level (Piponov et al., 2016).

The purpose of this study was to precisely determine the anatomical size and orientation of the glenoid, as well as quantify any variation based on gender in the Chilean population.

\section{MATERIAL AND METHOD}

Sample. One hundred and thirty-eight shoulder CT scans from asymptomatic Chilean patients without any history of shoulder pathology or surgery were obtained by random sampling from our institution CT database. 16 studies (11.6 $\%$ ) were excluded for incomplete images of the glenoid and coracoid, poor quality, artifacts or signs of structural or degenerative changes. $122 \mathrm{CT}$ scans were finally processed. The mean age was 43.8 years (SD 12.3; range, 17-53 years) with 63 female and 59 male patients.

\footnotetext{
${ }^{1}$ Shoulder and Elbow Unit. Instituto Traumatológico, Santiago, Chile.

${ }^{2}$ Department of Orthopedics and Trauma. Universidad de Chile, Santiago, Chile.

${ }^{3}$ Shoulder and Elbow Unit. Pontificia Universidad Católica de Chile, Santiago, Chile.

${ }^{4}$ Department of Orthopedics and Trauma. Pontificia Universidad Católica de Chile, Santiago, Chile.
} 
CT data acquisition and processing. Patients were scanned in a Siemens SOMATOM® Definition AS Open (Siemens Medical Solutions USA, Malvern, PA). The patients were placed in a supine anatomic position (Gantry tilt $0^{\circ}$ ) and images were obtained in $1-\mathrm{mm}$ increments (in-plane resolution, 0.27 to $0.35 \mathrm{~mm}$ ) along the axial axis of the human body. The images were acquired at $80-120 \mathrm{kVp}, 200 \mathrm{~mA}$, with a 500-mm field of view (FOV), 512 matrix resolution, and rotation speed of 0.5 seconds per revolution. The FOV of each scan included the entire scapula. Images were processed with ImageJ software.

Morphometric measurements. For each of the scapulae, eight morphometric measurements were obtained: glenoid version angle (GVA), glenoid inclination angle (GIA), maximum glenoid width (MGW), superior glenoid width (SGW), maximum glenoid height (MGH), glenoid surface area (GSA), glenoid vault depth (GVD), and maximum scapular width (MSW). We then calculated the ratio between MGH and SGW with MGW.

The GVA was measured with the "vault method" (Poon \& Ting, 2012). The scapular rotation was assessed on the scout view by ensuring the glenoid articular face is perpendicular to the CT axial slice. The mid-glenoid axial CT slice was identified by choosing the slice which correlated best to the midpoint of the glenoid face from superior to inferior on the scout view. The landmarks for measurement were based within the endosteal vault of the glenoid. An isosceles triangle was drawn within the medial end of the endosteal vault (Fig. 1).

A line was drawn from the medial corner bisecting this triangle symmetrically and a perpendicular line was drawn against this; this line was defined as the line of neutral version from which the actual glenoid version will be measured. Finally, a line parallel to the glenoid endosteal face was drawn and the angle at which this line bisected the line of neutral version gave us the GVA (Fig. 1). If the posterior margin of the glenoid was medial to the line of neutral version, the angle was defined as retroversion. Anteversion was assigned a positive value and retroversion was assigned a negative value.

The GIA was measured by the beta angle between the glenoid fossa and the cortical edge of the supraspinatus fossa in a coronal CT slice in the scapular plane. The midglenoid coronal CT slice was identified by choosing the slice which correlated best to the midpoint of the glenoid face from anterior to posterior in the sagittal view. The landmarks for measurement were the supraglenoid and infraglenoid tubercles. A line was drawn from the supraglenoid tubercle to the infraglenoid tubercle; this line was defined as the line

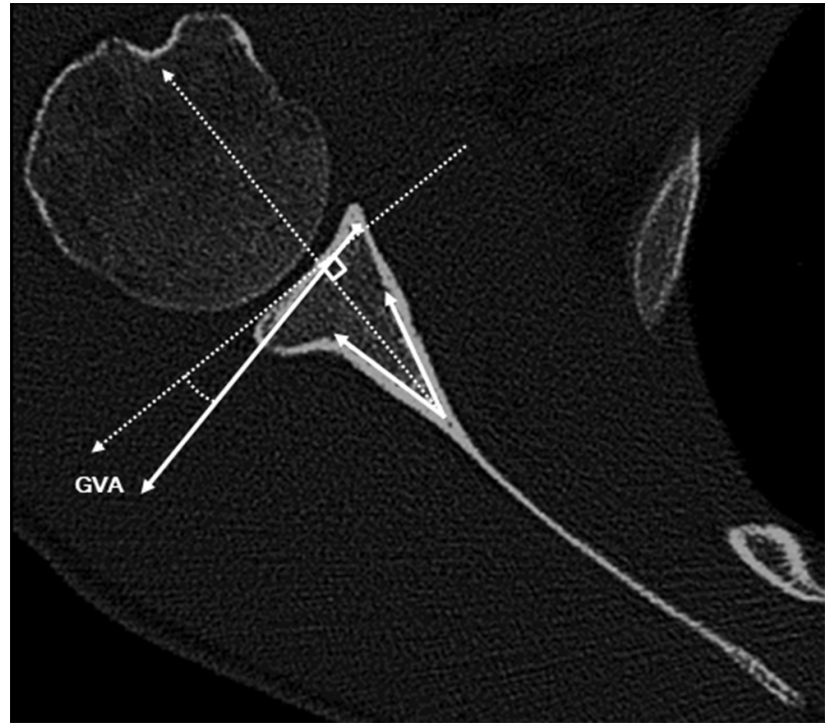

Fig. 1. Glenoid version.. The glenoid version angle (GVA) was measured with the "vault method" in the mid-glenoid axial CT slice identified by choosing the slice which correlated best to the midpoint of the glenoid face from superior to inferior on the scout view. The landmarks for measurement were based within the endosteal vault of the glenoid. An isosceles triangle was drawn within the medial end of the endosteal vault. A line was drawn from the medial corner bisecting this triangle symmetrically and a perpendicular line was drawn against this; this line was defined as the line of neutral version from which the actual glenoid version will be measured. Finally, a line parallel to the glenoid endosteal face was drawn and the angle at which this line bisected the line of neutral version gave us the angle of glenoid version.

of inclination. Finally, a line parallel to the scapular spine from the trigonum to the center of the glenoid was drawn and the angle at which this line bisected the line of inclination gave us the angle of glenoid inclination. In addition, the length of this line gives us the MSW (Fig. 2).

The MGW, SGW, MGH and GSA were measured in a sagittal CT slice in the scapular plane "en face" view. The glenoid surface CT slice was identified by choosing the slice which correlated best to the "en face" view of the glenoid face from medial to lateral in the coronal view. The landmarks for measurement were the supraglenoid and infraglenoid tubercles for the $\mathrm{MGH}$; the diameter of the bestfitting inferior glenoid circle for the MGW; the superior tangent of the best-fitting inferior glenoid circle perpendicular to the MGH for the SGW. The GSA was considered elliptical and was calculated with software tools (Figs. 3 and 4).

The GVD was measured in a CT axial slice. The midglenoid axial CT slice was identified by choosing the slice which correlated best to the midpoint of the glenoid face 

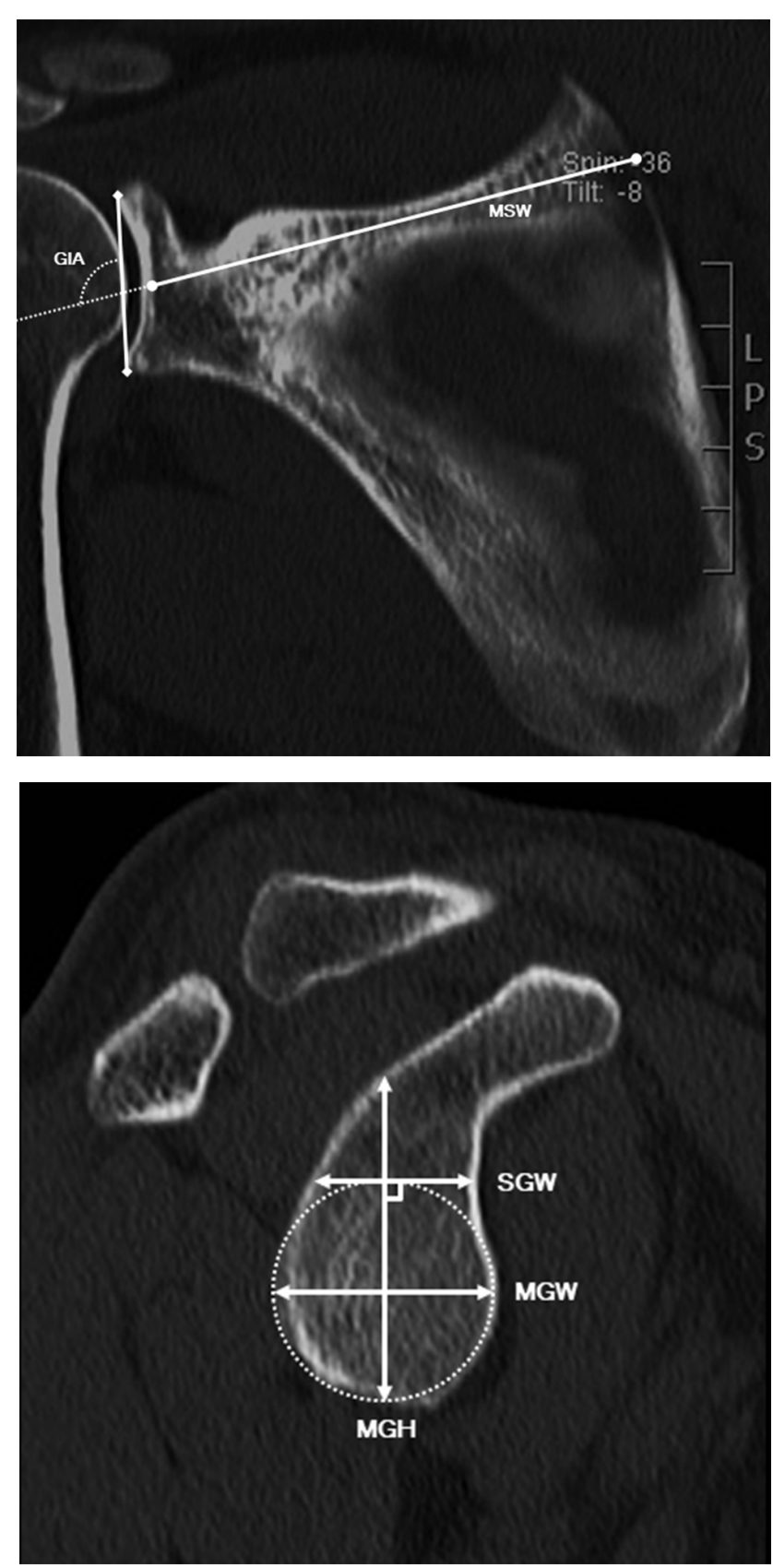

from superior to inferior in the scout view. A line was drawn perpendicular to the glenoid surface from the center of the glenoid to the vault; where this line intersected endosteal bone was defined as the GVD (Fig. 5).

Analysis of CT images. All the images were measured by a shoulder and elbow surgeon ( 5 years of practice and 10 years of experience with ImageJ software). For evaluation of the reproducibility of the measurements, $30 \mathrm{CT}$ scan were re-evaluated in a blinded mode. The glenoid dimensions were all found to measure within $0.2 \mathrm{~mm}$ of the original measurements. Of the GVA measurements, 22 were identical
Fig. 2. Glenoid inclination and scapular width. The glenoid inclination angle (GIA) was measured by the beta angle between the glenoid fossa and the cortical edge of the supraspinatus fossa in a coronal CT slice in the scapular plane. The mid-glenoid coronal CT slice was identified by choosing the slice which correlated best to the midpoint of the glenoid face from anterior to posterior in the sagittal view. The landmarks for measurement were the supraglenoid and infraglenoid tubercles. A line was drawn from the supraglenoid tubercle to the infraglenoid tubercle; this line was defined as the line of inclination. Finally, a line parallel to the scapular spine from the trigonum to the center of the glenoid was drawn and the angle at which this line bisected the line of inclination gave us the angle of glenoid inclination. In addition, the length of this line gives us the maximum scapular width (MSW).

Fig. 3. Glenoid size. Maximum glenoid width (MGW), superior glenoid width (SGW) and maximum glenoid height (MGH) were measured in a sagittal CT slice in the scapular plane "en face" view. The glenoid surface CT slice was identified by choosing the slice which correlated best to the "en face" view of the glenoid face from medial to lateral in the coronal view. The landmarks for measurement were the supraglenoid and infraglenoid tubercles for the $\mathrm{MGH}$; the diameter of the best-fitting inferior glenoid circle for the MGW and the superior tangent of the best-fitting inferior glenoid circle perpendicular to the MGH for the SGW. The GSA was considered elliptical and was calculated with software tools in a sagittal CT slice in the scapular plane "en face" view.

and the remaining 8 were within $0.3^{\circ}$. The GIA results were similar whereby 19 of the repeat measurements were identical and 11 were within $0.5^{\circ}$ of the original value.

Statistical analysis. Data are presented as mean \pm SD and was calculated the coefficient of variation $(\mathrm{CV})$. The Kolmogorov-Smirnov test and Shapiro-Wilk test revealed a normal distribution. Differences between genders were evaluated with an unpaired t-test with Welch's correction using GraphPad Prism 8. A p $<0.05$ was considered significant. Ethics committee of our institution approved this study. 


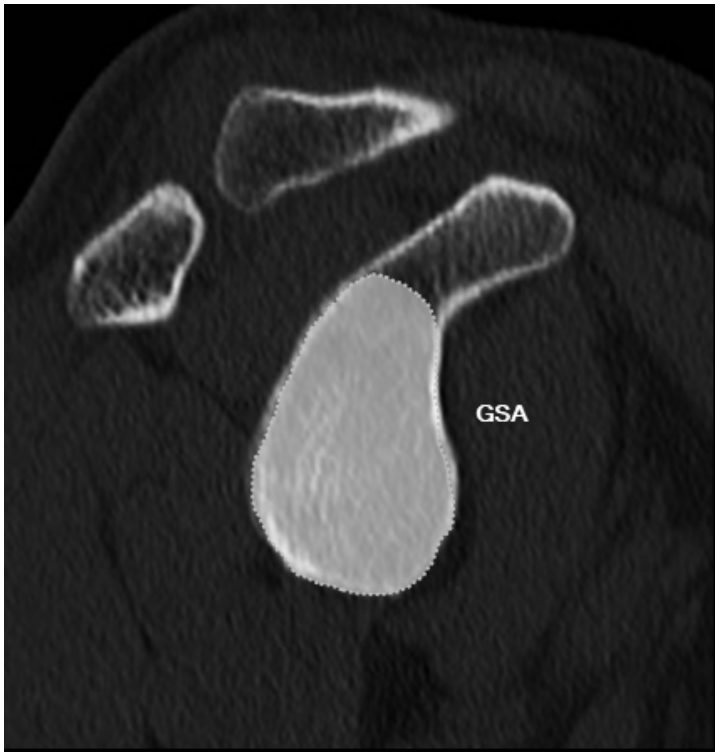

Fig. 4. Glenoid surface area. Glenoid surface area (GSA) was measured in a sagittal CT slice in the scapular plane "en face" view. The glenoid surface CT slice was identified by choosing the slice which correlated best to the "en face" view of the glenoid face from medial to lateral in the coronal view. The GSA was considered elliptical and was calculated with software tools in a sagittal CT slice in the scapular plane "en face" view.

\section{RESULTS}

The glenoid size showed an average MGW of $26 \pm$ $2.7 \mathrm{~mm}$, a MGH of $40.3 \pm 3.5 \mathrm{~mm}$ and a GVD of $26.5 \pm 3.7$ $\mathrm{mm}$. There were significant differences between men and women (Table I and II).

The ratio between $\mathrm{MGH}$ and $\mathrm{MGW}$ was $1.6 \pm 0.1$ (with no significant differences between men and women). The ratio between SGW and MGW was $0.7 \pm 0.1$ (and

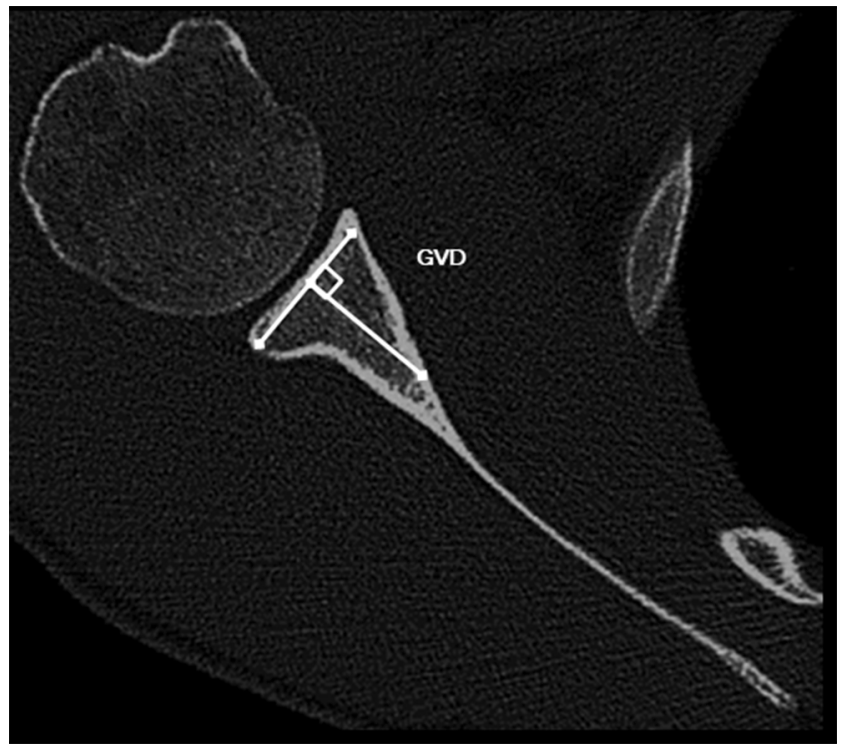

Fig. 5. Glenoid vault depth. The glenoid vault depth (GVD) was measured in a CT axial slice. The mid-glenoid axial CT slice was identified by choosing the slice which correlated best to the midpoint of the glenoid face from superior to inferior in the scout view. A line was drawn perpendicular to the glenoid surface from the center of the glenoid to the vault; where this line intersected endosteal bone was defined as the GVD.

\begin{tabular}{lcccccc}
\hline & \multicolumn{3}{c}{ MGW (mm) } & \multicolumn{3}{c}{ MGH $(\mathrm{mm})$} \\
& Total & Male & Female & Total & Male & Female \\
\hline Mean & 26.0 & $27.5^{*}$ & $24.5^{*}$ & 40.3 & $42,6^{*}$ & $37,8^{*}$ \\
SD & 2.7 & 2.9 & 1.4 & 3.5 & 3,0 & 2,2 \\
Max & 34.3 & 34.3 & 28.3 & 48.5 & 48,5 & 43,4 \\
Min & 20.8 & 20.8 & 21.9 & 34.6 & 35,7 & 34,6 \\
CV & 10.5 & 10.5 & 5.7 & 8.8 & 7,0 & 5,7 \\
& \multicolumn{7}{c}{ SGW (mm) } & & & & \\
\hline & 18.8 & $20.5^{*}$ & $17.0^{*}$ & 7.3 & $8.3^{*}$ & $6.3^{*}$ \\
Mean & 2.7 & 2.4 & 1.8 & 1.5 & 1.3 & 0.8 \\
SD & 25.2 & 25.2 & 20.4 & 11.4 & 11.4 & 8.4 \\
Max & 13.6 & 13.6 & 14.7 & 4.7 & 4.7 & 5.1 \\
Min & 14.6 & 11.8 & 10.6 & 20.2 & 16.1 & 12.3 \\
CV & \multicolumn{7}{c}{} & & & & & \\
\hline
\end{tabular}

Table I. Glenoid size. For each of the scapulae, were obtained maximum glenoid width (MGW), superior glenoid width (SGW), maximum glenoid height (MGH) and glenoid surface area (GSA). Significant differences between men and women were seen for MGW, MGH, SGW and GSA ( $p<0.05)$. SD: Standard deviation; $\mathrm{CV}$ : Coefficient of variation. 
Table II. Glenoid orientation, vault depth and scapular width. For each of the scapulae, were obtained glenoid version angle (GVA), glenoid inclination angle (GIA), glenoid vault depth (GVD), and maximum scapular width (MSW). Significant differences between men and women were seen for GVA and GVD ( $\mathrm{p}<0.05)$. SD: Standard deviation; CV: Coefficient of variation.

\begin{tabular}{lcccccc}
\hline & \multicolumn{3}{c}{ GVA (degrees) } & \multicolumn{3}{c}{ GIA (degrees) } \\
& Total & Male & Female & Total & Male & Female \\
\hline Mean & -13.9 & $-14.8^{*}$ & $-13.1^{*}$ & 11.1 & 10.9 & 11.3 \\
SD & 4.8 & 5.8 & 3.4 & 4.7 & 5.1 & 4.3 \\
Max & 3.0 & 3.0 & -4.4 & 22.6 & 22.6 & 19.2 \\
Min & -27.0 & -27.0 & -18.9 & 2.6 & 3.2 & 2.6 \\
CV & 34.2 & 38.9 & 26.3 & 42.2 & 46.7 & 38.1 \\
& \multicolumn{7}{c}{ GVD (mm) } & & \multicolumn{4}{c}{ MSW (mm) } \\
\hline Mean & 26.5 & $27.8^{*}$ & $25.3^{*}$ & 249.9 & 261.8 & 238.8 \\
SD & 3.7 & 3.6 & 3.4 & 65.8 & 76.6 & 52.0 \\
Max & 39.1 & 39.1 & 33.9 & 493.6 & 493.6 & 407.9 \\
Min & 20.9 & 20.9 & 21.4 & 142.6 & 176.7 & 142.6 \\
CV & 14.0 & 13.1 & 13.4 & 26.3 & 29.3 & 21.8 \\
\hline
\end{tabular}

\section{DISCUSSION}

This is the first Chilean study of size and orientation of the glenoid. Regarding the size of the glenoid in our sample, the width and height are values with low coefficient of variation, unlike the surface area. This is related to a greater variability of the data in the superior glenoid width, which can be interpreted as a greater morphological variability near to the base of the coracoid. In contrast, the central area and vault of the glenoid are largely constant.

Our measurements were consistent with those from previous reports. Churchill et al. performed a large-scale study (172 pairs of scapular bones) of the glenoid geometry by direct measurement using an electronic caliper. The male glenoid width and height were $27.8 \pm 1.6 \mathrm{~mm}$ and $37.5 \pm$ $2.2 \mathrm{~mm}$, respectively. The female glenoid width and height were $23.6 \pm 1.5 \mathrm{~mm}$ and $32.6 \pm 1.8 \mathrm{~mm}$, respectively. In comparison to our sample, the male width does not show any differences, however the male height and both female height and female width are different with statistical significance ( $\mathrm{p}<0.001)$. Chaijaroonkhanarak et al. (2019) in 264 adult-dried scapulae, showed similar results. It is important to consider whether the preparation is dry bone or fresh cadaver, since the latter may present with larger diameters influenced by hydration as well as labrum and cartilage remains (Mathews et al., 2017). Kwon et al. (2005) showed that the 3D CT images can accurately reflect the true anatomy of the glenoid, but the parameters where overestimated by $1.8 \pm 1.2 \mathrm{~mm}$ for width and by $1.4 \pm$ $1.1 \mathrm{~mm}$ for height. In an evaluation of 140 shoulders of patients who were a mean age of 75 years, Iannotti et al. (1992) reported a mean glenoid height of $39 \mathrm{~mm}$, a mean upper glenoid width of $23 \mathrm{~mm}$ and a mean lower glenoid width of $29 \mathrm{~mm}$, consistent with our findings. If we compare our results with the Japanese and French samples of Mizuno et al. (2017), our glenoid width is larger than the Japanese cohort, but smaller than the French, so we must consider ethnic differences in this type of measurement. However, the glenoid height is greater in both cases, so the glenoid of the Chilean population is more elongated. However, Matsuki et al. (2019) presented results very similar to our population suggesting that perhaps other factors (age, gender, height, method for measurement) bias the interpretation of these data.

As expected by the reported variability in superior glenoid width, glenoid articular surface area is reported with similar variation. In an evaluation of 32 cadaveric scapulae, Soslowsky et al. (1992) reported a mean GSA of $5.79 \mathrm{~cm}^{2}$ in male specimens and $4.68 \mathrm{~cm}^{2}$ in female specimens.

The glenoid size is larger in all measurements in the male subgroup. However, the ratio between width and height does not present significant differences which would be interpreted as a larger size, but proportional in shape. The only difference in form would be given to the area at the base of the coracoid (significant difference in the ratio between upper width and maximum glenoid width), which would be interpreted with a more circular shape in women and a pear-shape in men. Mathews et al. confirmed the sex dimorphism of glenoid size. This is reaffirmed by Merrill et al. (2009) and Pipinov et al. predicted, according to regression models, that males have $2.9 \mathrm{~mm}$ larger glenoid height compared to females and $3.4 \mathrm{~mm}$ higher glenoid width.

Regarding the glenoid orientation in our sample, the inclination and version are values with high coefficient of variation, unlike the glenoid size. The glenoid version was highly variable throughout the samples studied. Churchill et al. found lower values of upper inclination and retroversion of the glenoid $\left(-1.23^{\circ}\right)$, probably associated with the method of measurement used. Couteau et al. (2001) measured retroversion angle by using computed tomography (Friedman's method) in patients with rotator cuff pathology without bony changes $\left(-8^{\circ}\right.$, range, -17 to $\left.-2^{\circ}\right)$. Scalise et al. (2008) measured retroversion angle by using computed tomography (vault method) in 14 healthy subjects (10 male) with mean retroversion $-7.1^{\circ}$ (range, -15 to $-1^{\circ}$ ). Lewis \& Armstrong 
(2011) measured retroversion and inclination angles by using computed tomography (sphere fit method) in 20 normal glenoids with mean retroversion $-3.2^{\circ}$ and superior inclination $1.3^{\circ}$. This demonstrates the variability of the glenoid anatomy that may be encountered in clinical practice related to the methods used (Boileau et al., 2018).

The scapular body has independent ossification centers to the glenoid; therefore, the 2 parts of the scapula develop independently of each other (Landau \& Hoenecke, 2009). The method described by Friedman et al. (1992) for measuring glenoid version includes the scapular body. Consequently, this method is sensitive to the scapular body shape and orientation (Bryce et al., 2010). It should be considered as a "scapular version" rather than a true "glenoid version" (Matsumura et al., 2014).

We have used the "vault method" described by Poon \& Ting that without including the scapular body is easily accessible and can be reliably reproduced. Also, the base reference points are based within the medial endosteal triangle. This is important because the latter changes with glenoid version and medialization of the glenoid face, both of which occur as a result of glenoid bone erosion in arthritis, adding another element of variability to Friedman's method (Poon \& Ting). However, this method tends to slightly exaggerate glenoid retroversion (Poon \& Ting). Poon \& Ting using the "vault method" on 107 normal shoulders found a mean GVA of $-19 \pm 3^{\circ}$ of retroversion (range, -25 to $-9^{\circ}$ ). Using the same method, our sample shows a lower average degree of retroversion of statistical significance. Poon \& Ting concluded that there were no significant differences between gender, side, and age groups. In our sample, we found greater average retroversion in the male gender $\left(1.7^{\circ}\right)$ of statistically significant difference. Matsumura et al. using the "vault method" found a mean retroversion of $-8.9 \pm 2.7^{\circ}$ for normal shoulders.

The glenoid orientation is similar in both genders. There is a statistical difference in relation to GVA, but it is not clear whether this is of clinical relevance. Regarding the glenoid inclination in the coronal plane, there are no differences. Churchill et al. also did not find statistical differences in the angle of inclination and version according to gender. Churchill et al. reported considerable variability in glenoid inclination. In male specimens, the glenoid was superiorly inclined by $4^{\circ}$ (range, $7^{\circ}$ inferior - $15.8^{\circ}$ superior inclination) compared to the glenoid being superiorly inclined by $4.5^{\circ}$ in female specimens (range, $1.5^{\circ}$ inferior - $15.3^{\circ}$ superior inclination). In our sample, we found an inclination higher than that published by Churchill et al. In relation to the size of the scapula and the glenoid vault, the MSW is highly variable, however, the GVD is relatively more constant, which is favorable for planning surgery.

The strengths of our study include having a broad, healthy and gender-balanced sample. The weaknesses of our study relate to the method used (CT) which provides an approximation that may show variation with respect to reality. Additionally, we did not consider age, dominance, weight, height or nutritional status. The age-dependent variation of glenohumeral anatomy in the non-degenerated shoulder is largely unknown (Bockmann et al., 2016). In our sample the oldest patient is 53 years old, so this factor is probably not related to the results.

Understanding glenoid anatomical variations between genders and patients of different ethnicities will help surgeons set individual goals for every patient. Thesevariations could also be considered in designing personalized, patient-specific implants (Pipinov et al.). We can conclude that in this Chilean sample the morphological parameters of the glenoid correspond to the published literature, however, some characteristics in this cohort must be further investigated and confirmed using other methods of measurement.

CONTRERAS, J. ; LIENDO, R.; BELTRÁN, M. \& SOZA, F. Tamaño y orientación glenoidea en la población Chilena. Int. J. Morphol., 38(4):956-962, 2020.

RESUMEN: La morfología glenoidea es un factor clave para determinar el éxito de la cirugía de hombro. El propósito de este estudio experimental fue determinar con precisión el tamaño anatómico y la orientación de la glenoides en la población chilena. Se obtuvieron 122 tomografías computarizadas de pacientes chilenos asintomáticos. La edad media fue de 43,8 años (DE 12,3; rango, 17-53 años) con 63 pacientes femeninos y 59 masculinos. Para cada una de las escápulas, se obtuvieron la versión glenoidea y la inclinación, el ancho y la altura glenoidea máxima, el ancho glenoideo superior, el área de superficie glenoidea, la profundidad de la bóveda glenoidea y el ancho escapular máximo. El tamaño glenoideo mostró un ancho promedio de $26 \pm 2,7 \mathrm{~mm}$, una altura de $40,3 \pm 3,5 \mathrm{~mm}$ y una profundidad de bóveda de $26,5 \pm 3,7 \mathrm{~mm}$. Hubo diferencias significativas entre hombres y mujeres. La orientación glenoidea mostró un promedio de $-13,9 \pm 4,8^{\circ}$ de retroversión y una inclinación superior de $11,1 \pm 4,7^{\circ}$. Se observaron diferencias significativas entre hombres y mujeres solo para la versión. Concluimos que en esta muestra chilena los parámetros morfológicos de la glenoides corresponden a la literatura publicada, sin embargo, algunas características de esta cohorte deben confirmarse aún más utilizando otros métodos.

PALABRAS CLAVE: Articulación del hombro; Cavidad glenoidea; Anatomía; Retroversión ósea. 


\section{REFERENCES}

Bockmann, B.; Soschynski, S.; Lechler, P.; Ruchholtz, S.; Debus, F.; Schwarting, T. \& Frink, M. Age-dependent variation of glenohumeral anatomy: a radiological study. Int. Orthop., 40(1):87-93, 2016.

Boileau, P.; Cheval, D.; Gauci, M. O.; Holzer, N.; Chaoui, J. \& Walch, G. Automated three-dimensional measurement of glenoid version and inclination in arthritic shoulders. J. Bone Joint Surg. Am., 100(1):5765, 2018.

Bryce, C. D.; Davison, A. C.; Lewis, G. S.; Wang, L.; Flemming, D. J. \& Armstrong, A. D. Two-dimensional glenoid version measurements vary with coronal and sagittal scapular rotation. J. Bone Joint Surg. Am., 92(3):692-9, 2010.

Chaijaroonkhanarak, W.; Amarttayakong, P.; Ratanasuwan, S.; Kirirat, P.; Pannangrong, W.; Welbat, J. U.; Prachaney, P.; Chaichun, A. \& SaeJung, S. Predetermining glenoid dimensions using the scapular dimensions. Eur. J. Orthop. Surg. Traumatol., 29(3):559-65, 2019.

Churchill, R. S.; Brems, J. J. \& Kotschi, H. Glenoid size, inclination, and version: an anatomic study. J. Shoulder Elbow Surg., 10(4):327-32, 2001.

Codsi, M. J.; Bennetts, C.; Gordiev, K.; Boeck, D. M.; Kwon, Y.; Brems, J.; Powell, K. \& Iannotti, J. P. Normal glenoid vault anatomy and validation of a novel glenoid implant shape. J. Shoulder Elbow Surg., 17(3):471-8, 2008.

Couteau, B.; Mansat, P.; Mansat, M.; Darmana, R. \& Egan, J. In vivo characterization of glenoid with use of computed tomography. $J$. Shoulder Elbow Surg., 10(2):116-22, 2001.

Frankle, M. A.; Teramoto, A.; Luo, Z. P.; Levy, J. C. \& Pupello, D. Glenoid morphology in reverse shoulder arthroplasty: classification and surgical implications. J. Shoulder Elbow Surg., 18(6):874-85, 2009.

Friedman, R. J.; Hawthorne, K. B. \& Genez, B. M. The use of computerized tomography in the measurement of glenoid version. J. Bone Joint Surg. Am., 74(7):1032-7, 1992.

Iannotti, J. P.; Gabriel, J. P.; Schneck, S. L.; Evans, B. G. \& Misra, S. The normal glenohumeral relationships. An anatomical study of one hundred and forty shoulders. J. Bone Joint Surg. Am., 74(4):491-500, 1992.

Knowles, N. K.; Ferreira, L. M. \& Athwal, G. S. The arthritic glenoid: anatomy and arthroplasty designs. Curr. Rev. Musculoskelet. Med., 9(1):23-9, 2016

Kwon, Y. W.; Powell, K. A.; Yum, J. K.; Brems, J. J. \& Iannotti, J. P. Use of three-dimensional computed tomography for the analysis of the glenoid anatomy. J. Shoulder Elbow Surg., 14(1):85-90, 2005.

Landau, J. P. \& Hoenecke, H. R. Genetic and biomechanical determinants of glenoid version: implications for glenoid implant placement in shoulder arthroplasty. J. Shoulder Elbow Surg., 18(4):661-7, 2009.

Lewis, G. S. \& Armstrong, A. D. Glenoid spherical orientation and version. J. Shoulder Elbow Surg., 20(1):3-11, 2011.

Mathews, S.; Burkhard, M.; Serrano, N.; Link, K.; Häusler, M.; Frater, N.; Franke, I.; Bischofberger, H.; Buck, F. M.; Gascho, D.; et al. Glenoid morphology in light of anatomical and reverse total shoulder arthroplasty: a dissection- and 3D-CT-based study in male and female body donors. BMC Musculoskelet. Disord., 18:9, 2017.

Matsuki, K.; Sugaya, H.; Hoshika, S.; Ueda, Y.; Takahashi, N.; Tokai, M. $\&$ Banks, S. A. Three-dimensional measurement of glenoid dimensions and orientations. J. Orthop. Sci., 24(4):624-30, 2019.

Matsumura, N.; Ogawa, K.; Ikegami, H.; Collin, P.; Walch, G. \& Toyama, Y. Computed tomography measurement of glenoid vault version as an alternative measuring method for glenoid version. J. Orthop. Surg. Res., 9(1):17, 2014.

Merrill, A.; Guzman, K. \& Miller, S. L. Gender differences in glenoid anatomy: an anatomic study. Surg. Radiol. Anat., 31(3):183-9, 2009.

Mizuno, N.; Nonaka, S.; Ozaki, R.; Yoshida, M.; Yoneda, M. \& Walch, G. Three-dimensional assessment of the normal Japanese glenoid and comparison with the normal French glenoid. Orthop. Traumatol. Surg. Res., 103(8):1271-5, 2017.
Piponov, H. I.; Savin, D.; Shah, N.; Esposito, D.; Schwartz, B.; Moretti, V. \& Goldberg, B. Glenoid version and size: does gender, ethnicity, or body size play a role?. Int. Orthop., 4O(11):2347-53, 2016.

Poon, P. C. \& Ting, F. S. A 2-dimensional glenoid vault method for measuring glenoid version on computed tomography. J. Shoulder Elbow Surg., 21(3):329-35, 2012.

Scalise, J. J.; Codsi, M. J.; Bryan, J. \& Iannotti, J. P. The three-dimensional glenoid vault model can estimate normal glenoid version in osteoarthritis. J. Shoulder Elbow Surg., 17(3):487-91, 2008.

Soslowsky, L. J.; Flatow, E. L.; Bigliani, L. U. \& Mow, V. C. Articular geometry of the glenohumeral joint. Clin. Orthop. Relat. Res., (285):181-90, 1992

Strauss, E. J.; Roche, C.; Flurin, P. H.; Wright, T. \& Zuckerman, J. D. The glenoid in shoulder arthroplasty. J. Shoulder Elbow Surg., 18(5):81933, 2009.

Walch, G.; Badet, R.; Boulahia, A. \& Khoury, A. Morphologic study of the glenoid in primary glenohumeral osteoarthritis. J. Arthroplasty, 14(6):756-60, 1999

\section{Corresponding author:}

Dr. Julio Contreras Fernández

Shoulder and Elbow Unit

Instituto Traumatológico

Avda. Pocuro \#2170

Providencia

Santiago

CHILE

Email: juliocontrerasmd@gmail.com

Received: 15-12-2019

Accepted: 24-01-2020 